\title{
CORRELATION OF ANTHROPOMETRIC PARAMETERS AND BONE MINERAL DENSITY TO RISK OF NECK OF FEMUR FRACTURE RISK IN ELDERLY POPULATION.
}

\footnotetext{
1. MD, M.Phil

Assistant Professor Anatomy

Bacha Khan Medical College,

Mardan, Pakistan.

2. MBBS, M.Phil

Assistant Professor Anatomy

Ayub Medical College, Abbottabad,

Pakistan.

3. MBBS, FCPS

Associate Professor Anatomy

Bacha Khan Medical College, Mardan, Pakistan.

4. MBBS, M.Phil

Assistant Professor Anatomy

Bacha Khan Medical College,

Mardan, Pakistan.

5. MBBS, M.Phil

Assistant Professor Anatomy

Swat Medical College, Swat.
}

Correspondence Address:

Dr. Wajid Akbar

Assistant Professor Anatomy

Bacha Khan Medical College, Mardan,

Pakistan.

drwajidakbar@yahoo.com

Article received on:

19/02/2019

Accepted for publication:

25/06/2019

\begin{abstract}
Wajid Akbar ${ }^{1}$, Humaira Imtiaz ${ }^{2}$, Usman Ali ${ }^{3}$, Amna Halima ${ }^{4}$, Adnan Badar ${ }^{5}$
ABSTRACT: Objectives: This study is oriented upon the relation of anthropometric parameters and bone mineral density with femur neck fracture in the elderly. Study Design: Cross sectional study. Setting: Mardan Medical Complex, Mardan, Pakistan. Period: May 2015 to October 2015. Material \& Methods: A total of 121 patients both male and female from 50 to 70 years old were included in the study. Thirty patients had a history of hip fractures while 91 patients were age matched controls. Patients below 40 years and above 70 years were excluded as well as patients on long term steroids, or rheumatoid arthritis and bed ridden. Data regarding patient's age, sex as well as height and weight were recorded. Both height and weight were measured in light clothing without shoes. Weight was measured using an electronic scale and standing height was measured to the nearest centimeter with a stadiometer. Body mass index was calculated as weight $(\mathrm{kg}) /$ height $(\mathrm{m}) .^{2}$ Bone mineral density was assisted by Quantitative ultrasound (QUS) heel, using WHO T-score. The Anthropometric parameters and bone mineral density of hip fracture cases were then compared with age-matched control groups. For statistical analysis of data, we used SPSS 20. Results: The average age of hip fracture patients were higher than the control. Females with hip fracture found taller, lighter and had low BMI $(p=0.003)$. Bone mineral density of hip fracture cases were significantly lower as compared to T-score of control $(p=0.0001)$. Height correlated significantly with BMI $(r=2.68 p=0.005)$ and with BMD $(r=2.56 p=0.005)$. Weight had significant correlation with BMI $(r=0.488 p=0.0001)$ and with BMD ( $r=0.212 p=0.002)$. Conclusion: The anthropometric parameter, especially body mass Index and bone mineral density seems to be associated with the risk of femur neck fracture.
\end{abstract}

Key words: $\quad$ Body Mass Index, Bone Mineral Density, Femur Neck Fracture.

Article Citation: Akbar W, Imtiaz H, Ali U, Halima A, Badar A. Correlation of anthropometric parameters and bone mineral density to risk of neck of femur fracture risk in elderly population. Professional Med J 2020; $27(3): 517-522$. DOI: 10.29309/TPMJ/2020.27.3.3404

\section{INTRODUCTION}

One of the leading cause of morbidity and mortality in elderly is hip fracture especially neck of femur. The number of hip fractures are increasing day by day according to statistics. In 1990 number of hip fracture was 1.9 million and it will reach to 6.26 in 2050 , about half of which occurred in Asia with an incidence of 3 fractures per 10,000 populations per year. ${ }^{1}$ Although there are many causes of femur neck fractures but it can be broadly classified into bone mineral density dependent (BMD) and non-bone mineral density dependent (BMD) risk factors. There is a difference in bone remodeling in men and women with age: in men it is predominantly a sub periosteal growth while in women there is cortical thining. ${ }^{2,3}$
Tall individuals have high risk of hip fractures because of an increase in the distance from the surface of ground. ${ }^{4} \mathrm{~A}$ height of a person greater than $163 \mathrm{~cm}$ increases the hip fracture risk due to the high force intensity from a fall, which is equal to the square root of the falling height of a body. Decreased body weight leads to decreased body mass index and consequently less bone mineral density hence high risk of fractures, whereas obese individuals have less chances of hip fracture because of gluteo-femoral adipose tissue providing cushioning to the hip joint.5,6 Large meta-analysis of 12 prospective populationbased cohorts documented that the age-adjusted risk of a hip fracture increased 2-fold in older individuals with a BMI of $20 \mathrm{~kg} / \mathrm{m}^{2}$ compared with 
a BMl of $25 \mathrm{~kg} / \mathrm{m}^{2}{ }^{7}$ The existence of a positive association between body size and bone mass is well established. Relationship between body mass body mass index, weight, height, and BMD was reported for many populations. ${ }^{8}$

The microarchitecture, quality and bone mineral density indicates the strength of a bone. Bone mineralization and porosity are the two main dimensions of bone mineral density that can indirectly measure bone durability. ${ }^{9}$ Loss of bone mass is a very important characteristic concomitant to osteoporotic fractures; a study in which bone mineral density measured by DXA (dual x-ray absortiometry) reported that the risk of hip fracture increase by $50-150 \%$ with each standard deviation decline of bone mass density. ${ }^{10}$

\section{Rationale}

Thus the aim of our study is to know the association of Anthropometric parameters and bone mineral density index with femur neck fracture risk in the elderly population.

\section{MATERIAL \& METHODS}

The study was initiated after approval of Ethical Review Committee. This was a prospective cross sectional study; conducted in the department of orthopedics in Mardan Medical Complex Mardan, Pakistan. The duration of study was six months (from May 2015 to October 2015). The sample size was calculated by using the Epi-info version 6 / WHO software; the calculated sample size was; $n=121$. The sample size was 121 patients both male and female. The exclusion criteria were; participants who reported chronic medical conditions (osteoarthritis, metabolic diseases, renal failure, bilateral hip fractures, pathological (metastatic) hip fracture) or were using medications affecting bone metabolism or had family history of osteoporosis were excluded. Informed consent was obtained from each patient; all historical information was obtained by interviewing patients. Patient's age and sex were recorded; height and weight were measured of the participant in light clothing and without shoes. Weight was measured using an electronic scale and standing height was measured to the nearest centimeter with a stadiometer. Body mass index was calculated as weight $(\mathrm{kg}) /$ height $(\mathrm{m})^{2}$. The radiograph was taken at routine object film. Bone mineral density was tested using Calcaneal Ultrasonography (SONOSOT 300 with software version:3.03.06. Machine converted bone mineral density values into T-score and bone fragility was assessed using WHO T-score recommendations. The statistical software SPSS (version 20.0) was used for data analysis. The mean and standard deviation (SD) of the anthropometric parameters like age, sex, height, weight, and body mass index were tabulated for control and similarly for femur neck fracture cases.

\section{RESULTS}

Total of 121 patients both male and female were grouped into 91 controls and 30 hip fracture cases with age range of 50 to 70 years, among these 71 were male ( 16 cases and 55 control) and 50 were female (14 cases and 36 control) (See Table-I).

\begin{tabular}{|l|c|c|c|}
\hline \multirow{2}{*}{ Gender } & \multicolumn{2}{|c|}{ Cases and Control Group } \\
\cline { 2 - 3 } & Cases & Control & \\
\hline Male & 16 & 55 & 71 \\
Female & 14 & 36 & 50 \\
Total & 30 & 91 & 121 \\
\hline Table-I. Cases and control group distribution of study \\
subjects (n=121).
\end{tabular}

According to age brackets the subjects were ranged from 50 to 70 years, divided into two groups; 62 (14 patients and 48 control) were between the age of 50-59 years and 59 (16 cases and 43 control) were between the age of 59.1-70 years old. (See Table-II).

\begin{tabular}{|l|c|c|c|}
\hline \begin{tabular}{|} 
Age group/ \\
years
\end{tabular} & \multicolumn{3}{|c|}{ Cases and Control Group } \\
\cline { 1 - 3 } & Cases & Control & \\
\hline $50-59$ & 14 & 48 & 62 \\
$59.1-70$ & 16 & 43 & 59 \\
Total & 30 & 91 & 121 \\
\hline Table-II. Age group distribution of Cases and Control \\
group of study subjects $(\mathbf{n}=121)$.
\end{tabular}

The anthropometric indices (age, height, and weight and body mass index) of control group were found as; $\sim 58 \pm 6.49$ years, $163.48 \pm 11.6$ $\mathrm{cm}, 68.28 \pm 20.76 \mathrm{Kg}, 24.54 \pm 5.34 \mathrm{Kg} / \mathrm{m}^{2}$ and 
the mean bone mineral density T-score was $-1.2052 \pm 1.29$ respectively. (See Figure-1).

In case of hip fracture patients the values of anthropometric parameters (age, height, weight and $\mathrm{BMI})$ were found as; $60.03( \pm 7.43)$ years, 164( \pm 19.77$), 66.40(18.95) \mathrm{Kg}, 21.77(4.94) \mathrm{Kg} / \mathrm{m}^{2}$ respectively and the mean bone mineral density T-score was $-2.12(1.015)$ respectively. (See Figure-2).

Anthropometric measures in Males both controls and patients

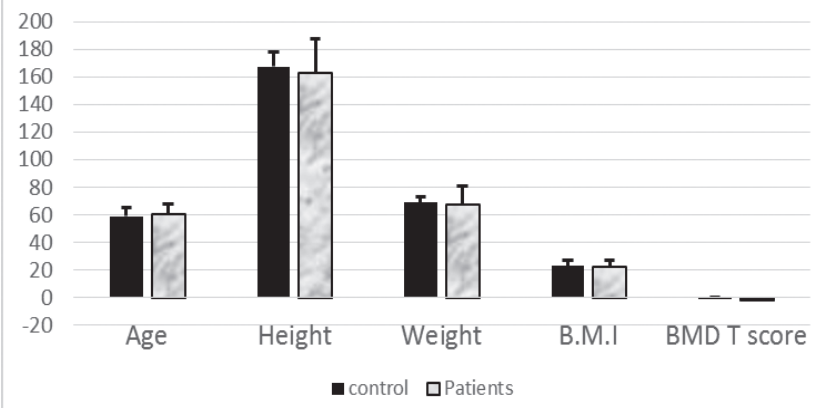

Figure-1. Comparison of Anthropometric parameters in male both controls and patients.

The mean values of anthropometric parameters and bone mineral density of control and cases were compared using t-test presented in table 5 .
Anthropometric measures in Females both controls and patients

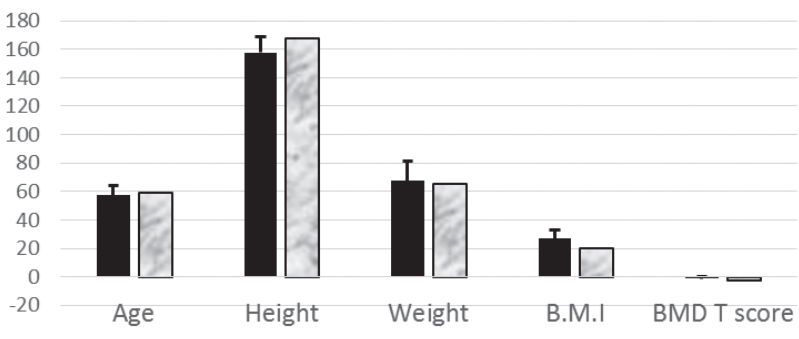

- control aPatients

Figure-2. Comparison of anthropometric parameters in females control and patients.

Mean height of females with cases are higher as compare to control but statistically are not significant. The mean body mass index of cases are significantly lower than control $(P<0.05)$ and the average bone mineral density of hip fracture cases were significantly lower than control $(p<0.001)$.

The Pearson's correlation coefficient among anthropometric parameters and bone mineral density was calculated to evaluate the relationship among the above parameters in control vs. patients as presented in Table-III.

\begin{tabular}{|c|c|c|c|c|c|}
\hline & Age & HT (cm) & WT (kg) & BMI & Tscore \\
\hline $\begin{array}{l}\text { Age Pearson } \\
\text { correlation } \\
\text { Sig.(2-tailed) } \\
\text { N }\end{array}$ & $\begin{array}{c}1 \\
121\end{array}$ & $\begin{array}{l}0.81 \\
0.37 \\
\\
121\end{array}$ & $\begin{array}{c}-2.68^{* \star} \\
0.001 \\
121\end{array}$ & $\begin{array}{c}-.311^{\star *} \\
0.001 \\
121\end{array}$ & $\begin{array}{c}-2.25 \\
0.004 \\
121\end{array}$ \\
\hline $\begin{array}{l}\text { HT Person } \\
\text { Correlation } \\
\text { Sig.(2-tailed) } \\
\mathrm{N}\end{array}$ & $\begin{array}{c}0.08 \\
0.379 \\
121\end{array}$ & $\begin{array}{c}1 \\
121\end{array}$ & $\begin{array}{c}0.109 \\
0.234 \\
121\end{array}$ & $\begin{array}{c}-.35^{\star \star} \\
0.000 \\
121\end{array}$ & $\begin{array}{l}0.09 \\
0.32 \\
121\end{array}$ \\
\hline $\begin{array}{l}\text { WT Person } \\
\text { Correlation } \\
\text { Sig.(2-tailed) } \\
\text { N }\end{array}$ & $\begin{array}{c}-.26 \\
0.003 \\
121\end{array}$ & $\begin{array}{c}0.10 \\
0.234 \\
121\end{array}$ & $\begin{array}{c}1 \\
121\end{array}$ & $\begin{array}{c}0.48^{\star *} \\
0.000 \\
121\end{array}$ & $\begin{array}{c}0.25 \\
0.005 \\
121\end{array}$ \\
\hline $\begin{array}{l}\text { BMI Person } \\
\text { Correlation } \\
\text { Sig.(2-tailed) } \\
\text { N }\end{array}$ & $\begin{array}{l}-.31 \\
0.001 \\
121\end{array}$ & $\begin{array}{c}-3.52^{\star *} \\
0.000 \\
121\end{array}$ & $\begin{array}{c}0.48 \\
0.000 \\
121\end{array}$ & $\begin{array}{c}1 \\
121\end{array}$ & $\begin{array}{l}0.10 \\
0.27 \\
\\
109\end{array}$ \\
\hline $\begin{array}{l}\text { Tscore Person } \\
\text { Correlation } \\
\text { Sig.(2-tailed) } \\
\text { N }\end{array}$ & $\begin{array}{c}-.25^{\star *} \\
0.004 \\
121\end{array}$ & $\begin{array}{c}0.09 \\
0.326 \\
121\end{array}$ & $\begin{array}{c}0.25^{\star *} \\
0.005 \\
121\end{array}$ & $\begin{array}{l}0.21^{*} \\
0.02 \\
121\end{array}$ & 121 \\
\hline
\end{tabular}




\section{DISCUSSION}

Anthropometric parameters like age, gender, body mass index, proximal femur geometrical indices and bone mineral density are of the reliable methods to evaluate the risks of hip fracture. The occurrence of hip fracture may be predisposed by anthropometric factors that increases with age. ${ }^{11}$ Our study shows that the mean age of fracture cases was predominantly 59-60 years. Vilas Bôas Junior et al found fracture risk age range from 60 to 69 years and was the one most affected $(\sim 37 \%))^{12}$ Rocha et al reported that greatest incidence of fractures among their elderly patients was in the age range from 71 to 80 years $(\sim 28 \%) . .^{13}$ Benetos et al observed that around $80 \%$ of the femur neck fractures occurred in women over the age of 70 years. ${ }^{14}$

Our study found that females with femur neck fracture were taller than the control group. A study of on Americans and Europeans reported that taller individuals have increased risk of hip fracture compared to short stature. ${ }^{15} \mathrm{~A}$ prospective study of 50000 Norwegian men and an investigation of postmenopausal women found that individuals with hip fracture were significantly taller than control. ${ }^{16}$ The mechanism by which height and hip axis length influences hip fracture may be mechanical; a stronger impact would occur because of the greater distance from the hip to ground level. One possible explanation for the relationship between body height and hip fracture is that tall people fall from a greater height (for standing falls), they would be expected to hit the ground surface at a greater velocity. ${ }^{17}$

We found body mass index of females with femur neck fracture cases are significantly lower than control which is consistent with earlier studies, that have shown that low body mass index is a risk factor for femur neck fracture..$^{18} \mathrm{~A}$ study conducted by Alfaro-Acha et al also reported that there was an inverse relationship between body weight and the risk of proximal femur fracture and stated that a $10 \%$ weight loss significantly increased the risk of hip fractures among individuals aged 65 years and over. ${ }^{19}$ De Laet et al found a small difference in the risk of fractures among their patients, in relation to an increase in body mass index of five units, from $25 \mathrm{~kg} / \mathrm{m}^{2}$ to $30 \mathrm{~kg} / \mathrm{m}^{2}$, the difference observed was a $17 \%$ decrease in the risk of hip fractures. ${ }^{20}$ Young et al concluded that low body mass index was a risk factor for femur neck fractures, while high body mass index was a protective factor. Margolis et al found a correlation between low body mass index or body size and increased risk of hip fractures. ${ }^{21}$ White et al and Holmberg et al reported an increased BMI was protective against hip fractures in both men and women. ${ }^{22}$

Our study found significantly lower bone mineral density in femur neck fracture cases as compared to controls. Body weight has been identified in previous reports as a predictor of peak bone mass in premenopausal women and a predictor of bone mineral density in older women. ${ }^{23}$ There is a strong inverse relationship between bone mineral density and fracture risk, with a 2-3 fold increase in fracture incidence for each standard deviation reduction in bone mineral density. ${ }^{24}$ Barret et al concluded that low bone mineral density is related to increased hip fracture risk in elderly and each one standard deviation decrease in peripheral bone mineral density T-score is related to 1.54 increased hip fractures. ${ }^{25}$ Our study is consistent with the study of Newton et al, Nakamura et al; in which BMD T-score of hip fracture cases significantly lower than control..$^{26}$ Faida et al also found lower T-score values postmenopausal women as compared to premenopausal. ${ }^{27}$

\section{LIMITATION OF THE STUDY}

One potential source of bias in the present study are residual confounding factors that include other known risk factors that we were unable to account for in our analysis like socioeconomic status, educational level, level of physical activity, smoking, vitamin D status, sex hormone levels, and nutrition. Moreover, unknown confounders cannot be adjusted for. Thus, the observed decreased risk of osteoporosis associated with BMI may be somewhat biased towards a positive correlation. Another limitation was that study participants were 50-70 years, and results may not apply to the broader age groups. Nevertheless, this study provides a baseline for future studies in a region of Pakistan that has very little research 
done on its population regarding BMD where we have to quote mostly data from the developed countries or other parts of Pakistan.

\section{CONCLUSION}

Anthropometric parameters, especially body mass index and bone mineral density associated with femur neck fracture in elderly. These parameters are easily measureable and should be taken into consideration for prevention as well as during treatment and rehabilitation.

\section{ACKNOWLEDGMENTS}

Authors acknowledge the immense help received from Dr. Humaira Imtiaz in data collection, Dr. Wajid Akbar in study design, Dr. Amna Haider in drafting manuscript and data interpretation and Dr. Usman Ali for critical review and approving final version of manuscript.

Copyright@ 25 June, 2019.

\section{REFERENCES}

1. Adnan RM, Zia MI. Frequency of femoral fractures; comparison in patients less than and more than 40 years of age. Professional Med J Feb 2012; 19(1): 011-014.

2. Orwig D, Hochberg MC, Gruber-Baldini AL, Resnick B, Miller RR, Hicks GE, Cappola AR, Shardell M, Sterling $R$, Hebel JR, Johnson R. Examining differences in recovery outcomes between male and female hip fracture patients: Design and baseline results of a prospective cohort study from the baltimore hip studies. The Journal of frailty \& aging. 2018 Jul 1; 7(3):162-9.

3. Pomeroy E, Mushrif-Tripathy V, Kulkarni B, Kinra S, Stock JT, Cole TJ, Shirley MK, Wells JC. Estimating body mass and composition from proximal femur dimensions using dual energy X-ray absorptiometry. Archaeological and Anthropological Sciences. 2018:13.

4. Levine IC, Pretty SP, Nouri PK, Mourtzakis M, Laing AC. Pelvis and femur geometry: Relationships with impact characteristics during sideways falls on the hip. Journal of biomechanics. 2018 Oct 26; 80:72-8.

5. NCD Risk Factor Collaboration. Trends in adult body-mass index in 200 countries from 1975 to 2014: A pooled analysis of 1698 population-based measurement studies with $\mathbf{1 9 \cdot 2}$ million participants. The Lancet. 2016 Apr 2; 387(10026):1377-96.
6. Nguyen TV, Center JR, Eisman JA. Osteoporosis in elderly men and women: Effects of dietary calcium, physical activity, and body mass index," Journal of Bone and Mineral Research 2000; 15(2):322-331.

7. Lloyd JT, Alley DE, Hochberg MC, Waldstein SR, Harris TB, Kritchevsky SB, Schwartz AV, Strotmeyer ES, Womack C, Orwig DL. Changes in bone mineral density over time by body mass index in the health ABC study. Osteoporosis International. 2016 Jun 1; 27(6):2109-16.

8. Fonseca $\mathrm{H}$, Moreira-Gonçalves $\mathrm{D}$, Coriolano $\mathrm{HJ}$, Duarte JA. Bone quality: The determinants of bone strength and fragility. Sports Medicine. 2014 Jan 1; 44(1):37-53.

9. Melton LJ III, Atkinson EJ. Determinants of bone loss from the femoral neck in women of different ages. $J$ Bone Miner Res 2000; 15:24-31.

10. WHO/IASO/IOTF, "The Asian-pacific perspective: Redefining obesity and its treatment," 2000.

11. Kulak CA, Dempster DW. Bone histomorphometry: A concise review for endocrinologists and clinicians. Arquivos Brasileiros de Endocrinologia \& Metabologia. 2010 Mar; 54(2):87-98.

12. Vilas-Bôas A Jr, Vercesi AE, Bodachne L. Estudo epidemiológico de fraturas de femur proximal em idosos. Acta Ortop Bras 1996; 4(3):122-6.

13. Rocha MA, Carvalho WS, Zanqueta C. Estudo epidemiológico retrospectivo das fraturas do fêmur proximal tratados no Hospital Escola da Faculdade de Medicina do Triângulo Mineir. Rev Bras Ortop 2001; 36(8):311-6.

14. Benetos IS, Babis GC, Zoubos AB. Factors affecting the risk of hip fractures. Injury 2007; 38(7):735-44.

15. Krueger D, Fidler E, Libber J, Aubry-Rozier B, Hans D, Binkley N. Spine trabecular bone score subsequent to bone mineral density improves fracture discrimination in women. Journal of Clinical Densitometry. 2014 Jan 1; 17(1):60-5.

16. Hemenway D, Feskanich D. Body height and hip fracture: A cohort study of 90,000 women. Int $\mathrm{J}$ Epidemiol 1995; 24:783-786.

17. Florschutz AV, Langford JR, Haidukewych GJ, Koval KJ. Femoral neck fractures: Current management. Journal of orthopaedic trauma. 2015 Mar 1; 29(3):121-9. 
18. McCloskey EV, Odén A, Harvey NC, Leslie WD, Hans D, Johansson $H$, Barkmann R, Boutroy S, Brown J, Chapurlat R, Elders PJ. A meta $\square$ analysis of trabecular bone score in fracture risk prediction and its relationship to FRAX. Journal of bone and mineral research. 2016 May; 31(5):940-8.

19. Alfaro-Acha A, Ostir GV, Markides KS. Cognitive status, body mass index, and hip fracture in older Hispanic adults. J Am Geriatr Soc. 2006; 54(8):1251-5.

20. De Laet $\mathrm{C}$, Kanis JA, Oden A, Johanson $\mathrm{H}$. Body mass index as a predictor of fracture risk: A meta-analysis. Osteoporos Int 2005; 16(11):1330-8.

21. Young $\mathrm{Y}$, Myers $\mathrm{AH}$, Provenzano G. Factors associated with time to first hip fracture. J Aging Health 2001; 13(4):511-26.

22. Holmberg $\mathrm{AH}$, Johnell $\mathrm{O}$, Nilsson PM, Nilsson J. Risk factors for fragility fracture in middle age. An prospective population-based study of 33,000 men and women. Osteoporos Int 2006; 17(7):1065-77.
23. Hawker GA., Jamal SA, Ridout R., Chase C. A clinical prediction rule to identify premenopausal women with low bone mass. Osteoporos Int 2002; 13(4):400406.

24. Melton LJ III, Atkinson EJ. Determinants of bone loss from the femoral neck in women of different ages. $J$ Bone Miner Res 2000; 15:24-31.

25. Barrett-Connor E, Siris ES. Osteoporosis and fracture risk in women of different ethnic groups. J Bone Miner Res 2005; 20:185-194.

26. Shane E, Burr D, Abrahamsen B, Adler RA, Brown TD, Cheung AM, Cosman F, Curtis JR, Dell R, Dempster DW, Ebeling PR. Atypical subtrochanteric and diaphyseal femoral fractures: Second report of a task force of the American Society for Bone and Mineral Research. Journal of Bone and Mineral Research. 2014 Jan; 29(1):1-23.

27. Farida Hafeez, Madiha Ahmad. Bone strength and its determinants in peri-and postmenopausal women. Pak J Physio 2011; 7(1).

\begin{tabular}{|c|c|c|c|}
\hline \multicolumn{4}{|c|}{ AUTHORSHIP AND CONTRIBUTION DECLARATION } \\
\hline Sr. \# & Author(s) Full Name & Contribution to the paper & Author(s) Signature \\
\hline 1 & Wajid Akbar & Study design. & \\
\hline 2 & Humaira Imtiaz & Data collection. & \\
\hline 3 & Usman Ali & Critical revision. & \\
\hline 4 & Amna Halima & Drafting Manuscript. & \\
\hline 5 & Adnan Badar & Data interpretation. & \\
\hline
\end{tabular}

